\title{
Society for Neuroscience reverses refund policy for in-person conference registrants
}

\section{BY PETER HESS}

\section{OCTOBER 2021}

The Society for Neuroscience (SfN) reversed its refund policy for the organization's annual meeting, following a social media outcry from would-be conference attendees. Those who no longer wish to attend the meeting can request a registration fee refund, the organization announced today.

Neuroscience 2021 was planned as a hybrid meeting, with sessions online from 8 to 11 November and in person from 13 to 16 November in Chicago, Illinois. On Friday, SfN announced that the inperson portion of the meeting had been cancelled because more than half of the presenters had backed out or were barred from traveling because of the ongoing coronavirus pandemic.

"When we made the decision to move ahead with in-person Neuroscience 2021 experience in the spring, vaccine optimism was high and the SARS-CoV-2 delta variant had not taken hold in the U.S., infection rates were low, and we believed that enthusiasm for an in-person meeting would be high and that international travel bans would be lifted," SfN president Barry Everitt wrote in today's statement. "We were wrong."

As Spectrum reported on Friday, the cancellation prompted a flurry of questions about registration fees, from researchers who said they had planned to attend the in-person portion of the meeting but did not want to pay the full registration price for a virtual conference.

SfN initially said it was offering 50 percent off the annual 2022 membership dues for anyone who had registered to attend in person. Those dues range from $\$ 32$ for undergraduates to $\$ 210$ for regular members. But registrants reacted quickly on social media, noting that this discount is a fraction of the $\$ 485$ meeting registration fee SfN charges its members - this number is higher for nonmembers and lower for student members and members from low-income countries. Today's update specifies that anyone can request a refund by 25 October. 


\section{Spectrum | Autism Research News}

https://www.spectrumnews.org

"SfN is reversing the previous 2021 refund policy that was communicated and this change in policy supersedes any prior communication. We apologize for the confusion and contradictory information," reads the updated cancellation announcement. SfN also noted that all who registered after the advance registration deadline of 4 October would pay only the advance registration price to attend the virtual sessions, and anyone who paid the higher price will be refunded the difference. Financial reasons did not drive decisions about having an in-person meeting or its subsequent cancellation, and SfN stands to lose a substantial sum of money, Everitt wrote in his announcement.

Researchers took to Twitter to voice their approval for the move but noted other concerns. Although SfN Housing automatically cancelled all hotel registrations, students and scientists will likely remain on the hook for other expenses, they say.

"Well done @SfNtweets for doing the right thing and changing policy regarding refunds for ECRs and others who were going to attend the cancelled in-person meeting," wrote Geraint Rees, professor of cognitive neuroscience at University College London in the United Kingdom. "This doesn't address non-refundable travel costs, but is a step in the right direction."

Well done@SfNtweets for doing the right thing and changing policy regarding refunds for ECRs and others who were going to attend the cancelled in-person meeting. This doesn't address non-refundable travel costs, but is a step in the right direction.

pic.twitter.com/R96mwPCL9T

—Geraint Rees (@profgeraintrees) October 11, 2021

Nonrefundable travel and lodging expenses may disproportionately affect trainees, says Amanda Kentner, professor of psychology at Massachusetts College of Pharmacy and Health Sciences in Boston. These reservations are often cheaper than refundable ones, making them especially attractive to trainees, she says. "I hope they can be supported by their institutions for reimbursement of these lost fees."

Others voiced concerns about whether SfN would refund abstract submission fees for registrants who had planned to attend or present in person.

"Unless I missed it, is SfN not refunding people's abstract submission fees?" wrote Mark D. Namba, a Ph.D. student at the University of Florida in Gainesville. "It doesn't make sense to refund people's registration without also refunding their abstract fees if they intend to withdraw from the conference entirely." 
Unless I missed it, is SfN not refunding people's abstract submission fees? It doesn't make sense to refund people's registration without also refunding their abstract fees if they intend to withdraw from the conference entirely.

—Mark D Namba (@MdNamba) October 11, 2021

"This is a great step, but many people would like to withdraw from the conference entirely and receive a refund for abstract fee $(\$ 140)$ as well," wrote Stephen Maren, professor of behavioral neuroscience at Texas A\&M University in College Station.

This is a great step, but many people would like to withdraw from the conference entirely and receive a refund for abstract fee $(\$ 140)$ as well. https://t.co/kBwHZ9MGp9

— ???? Brains of Steve ???? (@StephenMaren) October 11, 2021

The in-person meeting cancellation "stinks" for people who planned to go, says Audrey Brumback , assistant professor of neurology at the University of Texas at Austin, who was not planning to attend conference. "But, for the people who were planning on attending virtually, I think it'll be a much richer experience than a hybrid meeting would have been."

SfN did not immediately respond to request for comment.

Cite this article: https://doi.org/10.53053/ONDM6359 